\title{
Study the Role of Interleukin-4, Interleukin-17 and Interleukin-35 in Diagnosis and Prognosis of Preeclampsia in Egyptian Patients
}

A.M.Agha ${ }^{1}$, A.M.Abdelrahman ${ }^{1}$, A.M.Thabet ${ }^{1}$, B.E.Sakr ${ }^{2}$ and H.M.Ahmed ${ }^{1}$

${ }^{1}$ Clinical and Chemical Pathology Dept., Faculty of Medicine, Benha Univ., Benha, Egypt

${ }^{2}$ Gynecology and Obstetrics Dept., Faculty of Medicine, Benha Univ., Benha, Egypt

E-Mail:Heba@gmail.com

\begin{abstract}
Toxemia is a genuine entanglement of pregnancy, which is the reason for 60,000 maternal passings every year around the world. Notwithstanding the notable maternal hazard factors, for example, hypertension, diabetes mellitus, antiphospholipid neutralizer condition, heftiness, maturing, and various pregnancies, ongoing investigations have distinguished the job of hereditary and immunological elements in the pathogenesis of toxemia. PE could prompt maternal and pre-birth dismalness. Imbalanced cytokine arrange and modified degrees of a few fiery and calming cytokines have been accounted for in PE The examination intended to evaluate the serum levels of IL-4, IL-17 and IL-35 in toxemia patients well as in normotensive pregnant women.Blood tests were gathered from 25 toxemia patients and 15 normotensive pregnant ladies. Serum levels of IL-4, IL-17 and IL-35 in totally examined bunches were controlled by an immunoenzyrnatic test. The outcomes indicated higher groupings of IL-17 in PE and huge contrast between PE cases and control gathering and no noteworthy distinction in IL4 and IL35. A critical positive relationship was found between serum IL-17 and negative connection with maternal age, gravidity state, SBP and DBP.
\end{abstract}

\section{Introduction}

Toxemia is a pregnancy-explicit disorder that occurs in the last $50 \%$ of the pregnancy [1]. With the best dismalness and mortality, toxemia influences $5 \%$ to $7 \%$ of every single pregnant lady however is answerable for more than 70000 maternal passings and 500000 fetal passings worldwide consistently [2].

The clinical analysis depends on the improvement of new beginning hypertension (circulatory strain $\geq 140 / 90 \mathrm{mmHg}$ ) and proteinuria $(\geq 300 \mathrm{mg} / 24 \mathrm{hr})$ that happens from the twentieth seven day stretch of pregnancy [3]. Other maternal dysfunctions are additionally identified with PE, for example, renal inadequacy, liver association, neurological or hematological difficulties, uteroplacental brokenness or fetal development limitation $[4,5]$.

Toxemia adversely influences both the mother and baby. Concerning the last mentioned, toxemia may cause intra-uterine fetal development limitation (IUGR), placental unexpectedness, preterm conveyance and related inconveniences including, neonatal respiratory trouble condition, cerebral paralysis, necrotizing enterocolitis and even perinatal passing [6]. Other than its injurious effect on the embryo, toxemia likewise influences the pregnant lady, where it is related with hypertension, kidney harm, liver injury/disappointment, focal sensory system (CNS) harm, stroke, cardiomyopathy, pneumonic edema, HELLP disorder, grown-up respiratory misery condition, and even passing [7].

Toxemia is related with ceaseless insusceptible enactment that prompts an expanded creation of fiery cytokines by star incendiary $\mathrm{T}$ cells, and a decline in administrative and mitigating cytokines, which further advances a provocative state during PE [8].

Calming cytokines that help to control the invulnerable reaction, similar to interleukin IL-4, assumes a significant job in an ordinary, fruitful pregnancy by giving a parity to the insusceptible framework [9]. Different cytokines, for example, IL-17 which is a star fiery in nature and is typically emitted from Th17 cells during immunological difficulties, advance cytotoxic and provocative reactions $[10,11]$.

IL-35 is an inhibitory cytokine previously distinguished in 2007, which is delivered principally by CD4 Foxp3 Treg cells and required for the suppressive movement of administrative Tcell populaces [12]. IL-35 is likewise delivered by enacted B cells, tolerogenic dendritic cells and less significantly by actuated endothelial cells, smooth muscle cells, and monocytes [13, 14].

\section{Aim of the study}

The aim of the study to clarify the relation between the serum levels of IL-4, IL-17 as well as IL-35 and PE pathogenesis.

\section{Subjects and methods \\ Study Protocol}

The protocol was in conformity with the ethical guidelines of our institution and this study has the approval of the Research Ethics Committee (REC) at Benha faculty of medicine, Benha University. Written consent was obtained from all subjects following a full explanation of the procedure.

\section{Subjects}

The examination comprised of 40 pregnant ladies without past history of hypertension or obstetric and clinical inconveniences, admitted to Obstetrics and Gynecology division and outpatient centers, Benha University medical clinics, Benha, Egypt. Twenty five ladies were determined to have $\mathrm{PE}$, characterized as a relentless raised pulse estimation of 140/90 mmHgat two separate events, $6 \mathrm{~h}$ separated and proteinuria $(\geq 300 \mathrm{mg}$ in pee 
gathered during $24 \mathrm{hr}$ ) after the twentieth seven day stretch of development.A gathering of 15 normotensive Pregnant ladies with a simple pregnancy and who stayed normotensive (NT) and non-proteinuric until the finish of incubation were selected as controls and coordinated for gestational age at time of testing with the gatherings of ladies with PE. Gestational age was determined from the last menstrual period and affirmed by ahead of schedule (< 12 weeks development) ultrasound assessment.

\subsection{Methods}

All women were subjected to the following:

- History taking and clinical examination

- Blood pressure assessment, Systolic blood pressure (SBP) was identified and diastolic blood pressure (DBP) were identified.

- Laboratory investigation including ; complete blood count, 24 hour urine protein, SerumcytokinelevelsforIL-4, IL-17\& IL-35.

Four milliliters whole blood were collected by venipuncture from the antecubital vein and were put into a sterile plastic tube, divided to:

- one ml added to EDTA tube for CBC .

- The rest of blood was used for serum preparation for measurement of IL4,17,35 by ELIZA. using Quantikine ELISA kits from Sinobiological (China) for IL-4, IL17with catalogue no: KIT11846, KIT12047 respectively, while a high sensitivity commercial kit obtained from Biosource (China) Catalog No:

Briefly, the standard stocks were serially diluted in Reagent Diluent to generate 7 points for the standard curves. Diluted capture antibody was added to a microtiter plate. Plates were sealed and incubated overnight at room temperature, then washed with Wash Buffer.

Premixed standards or samples were added to each well, and incubated for overnight at $4^{\circ} \mathrm{C}$. After incubation and washing, premixed Detection Antibody was added to each well and the plate was incubated for $2 \mathrm{~h}$ at room temperature. After incubation and washing, Streptavidin-HRP was added to each well. The incubation was terminated after $20 \mathrm{~min}$ at room temperature. Then, Stop Solution was added to each well, and the optical density of each well was immediately determined using a microplate reader set to 450 run. The results were expressed in $\mathrm{pg} / \mathrm{mL}$.

\section{Statistical analysis}

The statistical analysis was performed by SPSS vs.25. (IBM, Armonk, New York, United states). Means and standard deviations or medians and ranges were used to assess numerical data. numbers and percentages for categorical data .

Comparisons between groups was done using independent $t$ test for normally distributed data or Mann Whitney $U$ test for ab-normally distributed numeric data.

Correlation analysis was done by using Pearson's or Spearman's correlation "when appropriate". " $r$ " is the correlation coefficient.

All $\mathrm{P}$ values were two sided. $\mathrm{P}$ values less than 0.05 were considered significant.

\section{Results}

Our study included; 25 Egyptian women, diagnosed with preeclampsia, In addition to 15 apparently healthy pregnant women as a control group.

There was no significant difference regarding maternal age, BMI, gestational age, gravidity and parity state between preeclamptic and control groups .Systolic blood pressure, diastolic blood pressure, mean arterial pressure and proteinuria were significantly higher in preeclampsia group compared to normotensive controls (P value $=<0.001$ ) as shown in Table (1).

Table (1) Demographic, clinical and laboratory features of the studied groups.

\begin{tabular}{lcccc}
\hline Variable & PE cases & $\begin{array}{c}\text { Control } \\
(\mathbf{n = 1 5})\end{array}$ & P value \\
\hline $\begin{array}{l}\text { Maternal age } \\
\text { (years) }\end{array}$ & Mean \pm SD & $30 \pm 3$ & $26 \pm 2$ & $<0.001$ \\
$\begin{array}{l}\text { Gestational age } \\
\text { (weeks) }\end{array}$ & Mean \pm SD & $29 \pm 4$ & $31 \pm 2$ & 0.032 \\
Gravidity & Median (range) & $3(1-6)$ & $2(1-4)$ & 0.15 \\
SBP & Mean \pm SD & $152 \pm 18$ & $91 \pm 13$ & $<0.001$ \\
DBP & Mean \pm SD & $101 \pm 13$ & $73 \pm 4$ & $<0.001$ \\
\hline
\end{tabular}

- Independent $\mathrm{t}$ test and Mann Whitney $\mathrm{U}$ test were used for normally and nonnormally distributed numeric variables respectively

- $\quad \mathrm{PE}=$ Pre-eclampsia

- $\quad \mathrm{SBP}=$ Systolic blood pressure
- $\quad \mathrm{DBP}=$ Diastolic blood pressure

The results showed that, serum IL4 and serum IL35 levels were lower in PE cases when compared to controls with no significant value $(\mathrm{p}$ value $=0.121$. 0.093) while serum IL17 was 
Table (2) Comparison between PE women and healthy pregnant women as regard serum level of IL-4,IL-17 and IL-35.

\begin{tabular}{lllll}
\hline & & $\begin{array}{l}\text { PE Cases } \\
(\mathbf{n = 2 5})\end{array}$ & $\begin{array}{l}\text { Controls } \\
(\mathbf{n}=\mathbf{1 5})\end{array}$ & P value \\
\hline IL 4 (Pg/ml) & Mean \pm SD & $8 \pm 1.2$ & $10.2 \pm 2.7$ & 0.121 \\
IL 17 (Pg/ml) & Mean \pm SD & $18.2 \pm 3.01$ & $8.38 \pm 1.02$ & $<0.001$ \\
IL 35 (Pg/ml) & Mean \pm SD & $262.2 \pm 32.0$ & $245.9 \pm 27.9$ & 0.093 \\
\hline
\end{tabular}

Table (3) Showed that serum IL-4 and serum IL35 were negatively correlated with maternal age, gravidity,SBP, and DBP, while serum IL17 showed significant positive correlation with maternal age, gravidity state, SBP and DBP.

Table (3) Correlations betweenIL-4, IL-17, IL-35 and the studied variables among patients group.

\begin{tabular}{lcccc}
\hline & & IL 4 (Pg/ml) & IL 17 (Pg/ml) & IL 35 (Pg/ml) \\
\hline Maternal age (years) & $\mathrm{r}$ & -.268 & 0.226 & -.156 \\
Gravidity & $\mathrm{P}$ value & 0.06 & 0.114 & 0.278 \\
& $\mathrm{r}$ & -.224 & 0.259 & -.089 \\
SBP & $\mathrm{P}$ value & 0.118 & 0.07 & 0.537 \\
& $\mathrm{r}$ & $-.503^{* *}$ & $.575^{* *}$ & $-.498^{* *}$ \\
DBP & $\mathrm{P}$ value & $<0.001$ & $<0.001$ & $<0.001$ \\
& $\mathrm{r}$ & $-.537 * *$ & $.658 * *$ & $-.588^{* *}$ \\
& $\mathrm{P}$ value & $<0.001$ & $<0.001$ & $<0.001$ \\
\hline
\end{tabular}

\section{Discussion}

Toxemia is a typical pregnancy explicit illness with potential unfavorable maternal and neonatal result that influences 3-5\% all things considered [16]. As of late, toxemia is re-characterized by once more hypertension showed following 20 weeks of development joined with one of the accompanying new-beginning conditions: proteinuria $(\geq 300 \mathrm{mg} /$ day); or maternal organ brokenness (counting renal inadequacy, liver association, neurological or hematological complexities); or uteroplacental brokenness (potential causing fetal development limitation) [1]. Two subtypes are clinically perceived when of beginning of the infection: beginning stage toxemia ( $<34$ weeks growth) and late beginning toxemia ( $\geq 34$ weeks incubation). Beginning stage toxemia is less predominant however has higher paces of maternal dismalness, perinatal demise and serious neonatal bleakness contrasted with the late beginning infection [18].

Our investigation exhibited that no distinction between PE case and controls in regards to the mitigating cytokines IL-4\& IL-35 levels, while the proinflammatory cytokines IL-17 levels were altogether expanded in patients with PE. These outcomes recommend a possible prevalent job of Th17 cells in the PE patients. These outcomes affirm the past confirmations by Ribeiro et al. (2017) who demonstrated an irregularity between CD4+ T lymphocyte subsets in PE [19]. As per Fig-ueiredo\& Schumacher Th17 and Treg cells structure perplexing and dynamic systems to look after homeostasis. These phones interface with other cell types to balance the ideal insusceptible reaction during pregnancy. Nonetheless, in PE, this complex doesn't happen appropriately on the grounds that there is a lopsidedness between the incendiary and calming profiles of CD4 + T-cell subsets [20].

High serum level of IL17 in ladies with PE contrasted with normotensive pregnant ladies was additionally detailed in past investigations $(21,22$, and 23). Likewise expanded levels was appeared in PE patients contrasted with non-pregnant ladies [24].

High serum IL-17 levels that was found in toxemia may brought about by summed up intravascular provocative response in toxemia. IL17 was demonstrated that it was included pathogenesis some immune system and provocative issues, for example, foundational lupus erythematosus, incendiary inside sickness just as rheumatoid joint pain [25].

Rather than our examination, a past report to decide the degree of IL-17 by ELISA in plasma by Ozkan et al tests of 40 preeclamptic and 40 normotensive pregnant ladies .The creators discovered lower IL-17 levels in the preeclamptic gathering. In any case, gestational age in their benchmark group was essentially higher than that of the preeclamptic gathering [26].

The centralization of IL-4and IL35 in our investigation demonstrated no noteworthy distinction between normotensive ladies and preeclamptic ladies. 
Our outcomes concurred with Jonsson.(2005) who showed that there were no measurable contrasts in the recoloring force for IL-4between placental segments from ladies with toxemia and from ladies with ordinary pregnancies [27].

Rein et al. (2002) couldn't distinguish contrasts between ladies with toxemia and ladies with typical pregnancies in regards to the phorbol-12 myristate-13 acetic acid derivation (PMA)prompted intracellular articulation of IFN-y and IL-4 in T-cells [28].

Additionally Henriques et al. (1998) were additionally ready to distinguish IL-4, however in placental tissues. Notwithstanding, they couldn't identify any distinction between placentas from preeclamptic pregnancies and those from typical pregnancies [29].

In a past report, Batebi et al. (2019) demonstrated that the degree of IL-35 was fundamentally expanded inside sera tests from preeclamptic ladies in a gathering of Iranian ladies with toxemia [30] .

On the opposite Ozkan et al.(2014) who discovered IL-35 and IL-17 degrees of preeclamptic ladies were essentially lower [26].

In the current examination, we found that serum level of IL-4 just as serum IL35 were contrarily corresponded with maternal age, gravidity, SBP and DBP. Though serum level of IL17 were decidedly associated with maternal age, gravidity, SBP and DBP.

These outcomes was in steady with an investigation performed by Cao et al. (2018)(31), as plasma level of IL-17 was in a positive reation with DBP, BMI and proteinuria in diabetic toxemia.

\section{Conclusion}

In our study the serum levels of the antiinflammatory cytokines IL-4 and IL-35 have been shown no significant difference in preeclampsia when compared to normal pregnancy, while IL-17 was markedly increased in PE.

Taken together, the homeostasis between Th17 and Treg cells might be essential for the fetus to be tolerated within the maternal environment. The imbalance of anti-inflammatory/proinflammatory cytokines plays an important role in the process of preeclampsia. The mechanism underlying the shift in cytokine profiles in preeclampsia remains undefined, but as the changes described here are likely to have evolved in vivo over time, they reflect the influence of a number of factors, including Thl7/Treg cells, IL-17, and IL-35 cytokines in the periphery of PE.

It seems IL 17 has a potential effect to maternal endothelium-associated inflammation may provide a biomarker for rapid preeclampsia diagnosis before progression of the disease to the late-onset stage.

While understanding the etiology and pathophysiology of PE is certainly of interest from a basic medical science perspective, it also has important implications for the treatment and management of this dangerous complication. There is renewed optimism that basic and clinical research which has helped elucidate the pathogenesis of this disease will lead to the rational design of interventions for the management and treatment of this important and common complication of pregnancy.

\section{References}

[1] ACOG Practice Bulletin No. 33Diagnosis and Management of Preeclampsia and Eclampsia. Obstetrics \& Gynecology, Vol.99,PP.159--67,2002.

[2] M.C.Hogan, K.J.Foreman, M.Naghavi, S.Y.Ahn, M.Wang, S.M.Makela, A.D.Lopez, R.Lozano, C.J.Murray. Maternal mortality for 181 countries, 1980-2008: a systematic analysis of progress towards Millennium Development Goal 5. Lancet. VOL.375, PP.1609-1623. doi: 10.1016/S0140-6736 (10)60518,12010.

[3] National High Blood Pressure Education Program Working Group on High Blood

[4] Pressure in Pregnancy. Report of National High Blood Pressure Education Program

[5] Working Group on high blood pressure in pregnancy. Am I Obstet Gynecol, Vol.183,PP.

[6] S1-22,2000.

[7] A.L.Tranquilli, G.Dekker, L.Magee, J.Roberts, B.M.Sibai, W.Steyn. The classification, diagnosis and management of the hypertensive disorders of pregnancy: a revised statement from the ISSHP. Pregnancy Hypertens, Vol.4,PP.97-104,2014.

[8] B.W.Mol, C.T. Roberts, S.Thangaratinam, L.A.Magee, C.J.de Groot, G.J.Hofmeyr. Preeclampsia. Lancet, Vol.387,PP.999$1011,2016$.

[9] C.H.Backes, K.Markham, , P.Moorehead, , L.Cordero, C.A.Nankervis, P.J. Giannone. Maternal preeclampsia and neonatal outcomes.J. Pregnancy 2011:214365, Vol. doi,PP.10.1155/2011/214365, 2011.

[10] L.Ghulmiyyah, B.Sibai. Maternal mortality from preeclampsia/eclampsia. Semin. Perinatol, Vol. 36, 56-59. Doi,PP.10.1053/j.semperi.2011.09.011,2012.

[11] N.Hanna, I.Hanna, M.Hleb, E.Wagner, J.Dougherty, D.Balkundi. Gestational agedependent expression of IL-10 and its receptor in human placental tissues and isolated cytotrophoblasts. Journal of immunology, Vol. 164(11),PP.5721-8. Epub 2000/05/23,2000. 
[12]T.G. Wegmann, H.Lin, L.Guilbert, T.R.Mosmann. Bidirectional cytokine interactions in the maternal-fetal relationship: is successful pregnancy a TH2 phenomenon? Immunol Today, Vol. 14(7),PP.353-6. Epub 1993/07/01. [PubMed: 8363725],1993.

[13] C.C.Zhou, R.A.Irani, Y.Dai, S.C.Blackwell, M.J.Hicks, S.M.Ramin .Autoantibodymediated IL-6-dependent endothelin-1 elevation underlies pathogenesis in a mouse model of preeclampsia. Journal of immunology, Vol. 186(10),PP.6024-34. Epub 2011/04/13, 2011.

[14] (11)G.Gadonski, B.B.LaMarca, E.Sullivan, W.Bennett, D.Chandler, J.P.Granger. Hypertension produced by reductions in uterine perfusion in the pregnant rat: role of interleukin 6. Hypertension, Vol. 48(4),PP.711-6. Epub 2006/08/31. [PubMed: 16940225],2006.

[15] M.Seyerl, S.Kirchberger, O.Majdic, J.Seipelt, C,Jindra, C.Schrauf. Human rhinoviruses induce IL-35-producing Treg via induction of B7-H1 (CD274) and sialoadhesin (CD169) on DC. Eur J Immunol.VOL, 40,PP.321-329. pmid:19950173,2010.

[16] H.Terayama, T.Yoshimoto, S.Hirai, M.Naito, N.Qu, N.Hatayama. Contribution of IL-12/IL35 common subunit p35 to maintaining the testicular immune privilege. PLoS One, Vol. 9,PP.e96120. pmid:24760014,2014.

[17] K.O.Dixon, S.W.van der Kooij, D.A.Vignali, C.van Kooten. Human tolerogenic dendritic cells produce IL-35 in the absence of other IL12 family members.Eur J ImmunolIn press, 2015.

[18] W.T.Friedewald, R.I.Levy, D.S.Fredrickson. Estimation of the concentration of low-density lipoprotein cholesterol in plasma, without use of the preparative ultracentrifuge. Clin Chem, Vol.18,P.499-502. [PubMed], 1972.

[19] C.V.Ananth, K.M.Keyes, R.J.Wapner. Preeclampsia rates in the United States, 19802010: age-period-cohort analysis. BMJ, Vol. 347,PP. f6564,2013.

[20] A.L.Tranquilli, G.Dekker, L.Magee, The classification, diagnosis and management of the hypertensive disorders of pregnancy: A revised statement from the ISSHP. Pregnancy Hypertens, Vol. 4(2),PP, 97-104, 2014.

[21] S.Lisonkova, Y.Sabr, C.Mayer, C.Young, A.Skoll, K.S.Joseph Maternal. morbidity associated with early-onset and late-onset preeclampsia. Obstet Gynecol, Vol.124(4),PP.771-81,2014.

[22] V.R. Ribeiro, M. RomaoVeiga, G. Romagnoli, M.L. Matias, P.R. Nunes, V. 1 Borges, J.C. Peracoli, M.T.Peracoli. Association between cytokine profile and transcription factors produced by $\mathrm{T}$-cell subsets in early- and late-onset pre-eclampsia .Immunology, Vol. 152(1),PP. 163-173,2017.

[23] A.S. Figueiredo, A. Schumacher. The T helper type 17/regulatory $\mathrm{T}$ cell paradigm in pregnancy. Immunology, Vol.148,PP.1321,2016.

[24] W.Cao, X.Wang, T.Chen, H.Zhu, W.Xu, S.Zhao, X.Cheng, L.Xia. The expression of Notch/Notch ligand, IL-35,IL-17 and Th17/Treg in preeclampsia. Disease markers, volume Article, Vol. ID ,PP.316182 - 9 pages, 2015.

[25] D.Darmochwal- Kolarz, M.Michalak, B.Kolarz, M.Przegalinska- kalamucka, A. Bojarska-Junak, D.Sliwa, J.Oleszczuk. the role of Interleukin-17, Interleukin -23, transforming growth factor- $\beta$ in pregnancy complicated by placental insufficiency. Biomed Research International, volume, Article ID ,PP.6904325, 5 pages, 2017.

[26] T.Poordast, F.S.Najib, R.Baharlou, A.Bijani, S.M.Alamdarloo, A.Poordast.Assessment of T helper 17-associated cytokines in third trimester of pregnancy. Iran J Immunol, Vol. 14(2),P.172-179,2017.

[27] A.Molvarec, I.Czegle, J.Szijártó, J.Rigó Jr. Increased circulating interleukin-17 levels in preeclampsia. J Reprod Immunol, Vol. 112,PP.53-7. [PubMed] ,2015.

[28] R.M.Onishi, S.L.Gaffen. Interleukin-17 its target genes. mechanisms of interleukin-17 function in disease. Immunology, Vol. 129,PP.311-21,2010.

[29]Z.S.Ozkan, M.Simsek, F.Ilhan, D.Deveci, A.Godekmerdan, E.Sapmaz. Plasma IL-17, IL-35, interferon- $\gamma$, SOCS3 and TGF- $\beta$ levels in pregnant women with preeclampsia, and their relation with severity of disease. $J$ Matern Fetal Neonatal Med, Vol. 27,PP.15137. [PubMed] ,2014.

[30](27) Y.Jonsson, M.Ruber, L.Matthiesen. Cytokine mapping of sera from women with preeclampsia and normal pregnancies. J Reprod Immunol, Vol. 70(12),PP.839110,2006.

[31](28). D.T.Rein, T.Schondorf, G U.J.ohring, C.M.Kurbacher, I.Pinto, M.Breidenbach, P .Mallmann, H.Kolhagen H.Engel. Cytokine expression in peripheral blood lymphocytes indicates a switch to $\mathrm{T}$ (HELPER) cells in patients with preeclampsia. J Reprod lmmunol , Vol.54 (1-2),PP.133-42,2002.

[32] (29).C.U.Henriques, G.E.Rice, M.H.Wong, K.Bendtzen. Immunolocalisation of interleuk:in-4 and interleukin-4 receptor in placenta and fetal membranes in association with pre-term labour and pre-eclampsia. Gynecol Obstet Invest , Vol.46 (3),P. 1727,1998. 
[33] A.Batebi, B.Namavar-Jahromi, M.Hassan Zadeh, M.Ahmadi, B.Gharesi-Fard, M. Hosseini. Evaluation of IL-17 and IL-35 Serum Levels in Patients with Preeclampsia: J Reprod Infertil, Vol. 20(4),PP.237-243,2019.
[34] W.Cao, X. Wang, T.Chen. Maternal lipids, BMI and IL-17/IL-35 imbalance in concurrent gestational diabetes mellitus and preeclampsia, Vol. 16(1),PP. 427-435, 2018. 